Aus der Chirurgischen Klinik des Ogata-Hospitals in Osaka (Japan).

\title{
Zur kosmetischen Behandlung der Naevi und der Teleangiektasien.
}

Von Dr. Kiichi Ogata, Chefarzt.

Zur Beseitigung der Naevi und der Teleangiektasien kann man die rerschiedensten Methoden anwenden. Die Mittel, welche heutzutage in allgemeinem Gebrauche stehen, sind: Elektrolyse, Aetzung mit rauchender Salpetersäure, Sublimatkollodium, Exstirpation, Radiumstrahlen etc. Diese Mittel empfeblen sich aus kosmetischen Rürksichten niclit im Gesicht, weil sie mehr oder weniger starke Narben hinterlassen, die oft mehr entstellen als die vorher vorhandenen Pigmentierungen.

Um dieser Eintstellung vorzubeugen, wende ich seit einigen Jahren ein Mittel, Maculanin, an. Damit habe ich die besten Resultate, insbesondere sehr gute kosmetische Effekte erzielt.

Die Darstellung des Maculanin ist folgende:

Man reinigt Reiskörner mit Wasser und legt sie in Abständen von $1 \mathrm{~cm}$ auf den Boden einer Glasschale. Darauf gießt man $10 \%$ Kaliumhydratlösung auf, bis sie vollständig aufgeweicht sind, dann läßt man sie 6--8 Stunder lang ruhig stehen. Die im Reis enthaltene Stärke quillt unter dem Einfluß von Kaliumbydrat auf und wird nach und nach durchsichtig. Wenn der ganze Teil des Reiskornes durchsichtig geworden ist, gießt man den Ueberschuß der Kalilöstung ab und spült ihn mit Wasser sorgfältig aus. Die so zubereitete Masse tut man in cinen porzellanenen Mörser und zerreibt sie vollkommen. Diese Masse nenne ich Maculanin. Es ist eine farblose, klebrige, gallertartige Masse, welche stark alkalisch reagiert und chemisch eine Verbindung der Stärke mit Kaliumhydrat: Kaliamylat darstellt.

Daß der wirksame Bestandteil des Maculanin Kali hydricum ist, versteht sich von selbst; es wirkt ätzend wie Aetzkali.

Bei der Aetzung mit Maculanin geht eine Heilung unter dem

1) Ueber einige Ergebnisse der experimentellen Tumorforschung. Zeitschrift für Krebsforschung 1907, Bd. V. 
Schorf von statten, während die reine Kalilauge in der Regel eine Eiterung verursacht. Diesen Unterschied der Effekte beider Mittel verdanken wir vornehmlich der mäßigen Aetzkraft der mit Stärke verbundenen Lauge, wodurch das Gewebe nicht zu tief angegriffen wird. Das Maculanin verliert oder verringert nach sechs Stunden seine A tetz wirkung, weshalb es jedesmal frisch zubereitet werden muß.

Die Ausführung der A etzung geschieht am besten mittels eines spitzen Glasstäbchens. - Man reinigt zuerst die Haut mit Seifenspiritus gründlich und trocknet sie dann gut ab. Nun taucht man das Glasstäbchen in das Maculanin und bestreicht mit dem Aetzmittel das pathologische Gewebe.

Die Behandlung beginnt in der Periplierie des kranken Gewebes, indem man die Grenze des gesunden und kranken Gewebes bestreicht, sonst bekommt man oft dort eine schmale Pigmentlinie.

Gewöhnlich führt man in einer Sitzung neehrmals einige Aetzungen aus. Beim erstenmal nimmt man keine Reizerscheinung wahr, das Präparat trocknet in kurzer Zeit. Hierauf wird die Applikationsstelle mit sterilisierter Kochsalzlösung abgespült, dann bestreicht man sie wieder mit Maculanin.

Vor der Wiederholung bepinselt man bei Kindern oder bei umfangreicheren Naevi die Flächen mit $5 \%$ Cocainlösung, um sie gegen die schmerzhafte Aetzung unempfindlich zu machen. Nach dem zweiten Vorgehen nehmen die Naevi tiefschwarze und die Feuermäler rotbraune Farbentöne an.

In den meisten Fällen genügt eine drei- bis fünfmalige Bestreichung, aber wenn das Pigment subkutan sitzt und von unveranderter Haut bedeckt ist, bedarf dieses Verfahren oftmals einer Wiederholung. Nach beendigtem Verfahren trocknet die Verschorfung von selbst ab, darüber braucht man keinen Verband zu tragen, man kann unbesorgt die Heilung abwarten. Der trockene Schorf beginnt nach. 7-10 Tagen an den Ränderı sich zu lösen worauf er sich in einigen Tagen in toto abstößt. Die Narben sind anfangs rötlich, blassen aber mit der Zeit ab und werden völlig unsichtbar, sodaß man keine Spur des Pigments mehr wahrnimmt. Man hüte sich, bei umfangreichen Naevi oder Teleangiektasien in jeder Sitzung zu große Teile zu ätzen, sonst entsteht eine grobe, häßlich $\theta$ Narbe, welche durch Eiterung bedingt wird. Umfangreiclıe Naevi oder Feuermäler bedürfen einer ziemlich langen Behandlung, und die Aetzung muß mit den notwendigen Pausen über Monate, ja auf ein ganzes Jahr und darüber ausgedehnt werden, bis eine Heilung definitiv vollendet ist.

Bei Angioma cavernosum hat man keine Heilung zu erwarten. Bei Tätowierungen erzielt man in einigen Sitzungen vortrefflichen Effekt. Zur Therapie von Vitiligo, parasitären Hautkrankheiten und Acne rosacea verwendet man auch unter Umständen das Maculanin erfolgreich. Mejne Erfahrungen hierüber sind noch nicht genügend. 